\title{
Baixas doses de glyphosate e seus efeitos no crescimento de Commelina benghalensis
}

\section{Low doses of glyphosate and its effects on Commelina benghalensis growth}

\author{
Dana Katia Meschede ${ }^{1 *}$, Edivaldo Domingues Velini ${ }^{2}$ Caio Antonio Carbonari ${ }^{1}$
}

\begin{abstract}
Resumo - Com o objetivo de verificar o efeito de baixas doses, simulando a deriva do herbicida glyphosate no crescimento e desenvolvimento inicial da Commmelina benghalensis foi realizado um trabalho em condições de casa-de-vegetação. A trapoeraba foi semeada superficialmente (aproximadamente $2 \mathrm{~cm}$ ) em tubetes preenchidos com substrato. Após a germinação, deixou-se apenas uma planta por tubete e realizou-se aplicação dos tratamentos. Os tratamentos foram constituídos por diferentes doses de glyphosate, 2, 4, 8, 16, 20 e 24 g e.a. ha ${ }^{-1}$ e uma testemunha sem aplicação. Pelos resultados obtidos pode-se verificar que em geral, doses a partir de $2 \mathrm{~g}$ e.a. $\mathrm{ha}^{-1}$ podem causar efeitos no crescimento e desenvolvimento da parte aérea e radicular de plantas de C. bengalensis.
\end{abstract}

Palavras-chave: Trapoeraba, deriva, EPSPs.

\begin{abstract}
With the objective of verifying the effect of low doses, simulating glyphosate herbicide drift in growth and initial development of Commmelina benghalensis, a study was conducted in greenhouse conditions. C. benghalensis was superficially sowed (approximately 2 $\mathrm{cm}$ ) in small tubes filled out with substratum. After the germination, just one plant by tube was kept and treatments were applied. Treatments were constituted by different glyphosate doses, 2 , 4, 8, 16, 20 and $24 \mathrm{~g}$ a.e. $\mathrm{ha}^{-1}$ and a check without application. By obtained results, it was possible to verify that, doses starting from $2 \mathrm{~g}$ a.e. $\mathrm{ha}^{-1}$ may cause effects in growth and development of dossel and roots of $C$. benghalensis plants.
\end{abstract}

Keywords: Wandering-jew, drift, EPSPs.

\footnotetext{
${ }^{1}$ *Pesq. Dra. FCA/UNESP, Fazenda Experimental Lageado s/n, CP237, 18603-970, Botucatu-SP. e-mail: meschede@fca.unesp.br

${ }^{2}$ Prof. Adjunto Dr., Depto. Produção Vegetal, FCA/UNESP, Faz. Experimental Lageado s/n, CP237, 18603-970, Botucatu-SP.
} 
Os herbicidas atuam sobre sistemas enzimáticos ou proteínas específicas das plantas alterando sua funcionalidade. As rotas em que atuam os herbicidas devem ser fundamentais para $o$ crescimento $e$ desenvolvimento vegetal, pois o seu bloqueio deve promover a paralisação do crescimento ou a morte das plantas. De modo análogo, o bloqueio parcial destas rotas, com uso de doses subletais dos herbicidas, também pode ter implicações importantes alterando o balanço de processos metabólicos nas plantas.

Comprova esta hipótese o fato de vários herbicidas terem sido originalmente desenvolvidos como reguladores de crescimento. Posteriormente, maiores doses ou compostos com maior atividade permitiram que a morte das plantas fosse produzida. $\mathrm{O}$ primeiro e mais notório exemplo é o do 2,4-D, originalmente desenvolvido como uma auxina e que em doses elevadas tem efeito herbicida (Mousdale \& Coggins, 1991).

Outro exemplo é o próprio glyphosate cujo antecessor, o glyphosine (utilizado no Brasil como maturador e com nome comercial Polaris ${ }^{\circledR}$ ), ainda é utilizado como regulador de crescimento em vários países. Na década dos 1970, observou-se que elevadas doses do glyphosine poderiam promover a morte das plantas. A partir desta informação, foi desenvolvido um novo composto com menores dimensões moleculares e com maior afinidade à enzima EPSPs (Halter, 2009).

O glyphosate é o único composto disponível comercialmente no Brasil que atua na enzima EPSPs (5-enolpiruvilchiquimato 3fosfato sintase, E.C. 2.5.1.19) na rota de síntese dos aminoácidos aromáticos e do ácido chiquimico. Trata-se de um herbicida sistêmico, não seletivo e de amplo espectro, com translocação via simplasto e com absorção facilitada por proteínas transportadoras de grupos fosfato, que estão presentes na membrana (Velini et al., 2009). A enzima
EPSPs é codificada no núcleo e desempenha sua função no cloroplasto (Stauffer et al., 2001), catalisando a ligação dos compostos chiquimato-3-fosfato e fosfoenolpiruvato produzindo o enolpiruvilchiquimato-3-fosfato e fosfato inorgânico (Peterson et al., 1996). Segundo Hess (1993) o glyphosate é um inibidor não competitivo e competitivo, respectivamente, com os dois substratos.

A inibição da EPSPs leva ao acúmulo de altos níveis de chiquimato nos vacúolos o que é exacerbado pela perda de controle de realimentação e pelo fluxo desregulado de carbono na rota. Segundo as informações apresentadas por Kruse et al., (2000), aproximadamente $35 \%$ da massa seca de plantas é representada por derivados da via do chiquimato e $20 \%$ do carbono fixado pela fotossíntese segue por essa rota metabólica.

Sendo assim, se elevadas doses do glyphosine podem produzir o efeito do glyphosate, deve ser esperado que pequenas doses do glyphosate produzam os efeitos do glyphosine. Corroborando com as informações apresentadas por Mauch et al. (2001) e Ruuhola \& Julkinen-Titto (2003), estudos preliminares com o bloqueio parcial da enzima EPSPs através da aplicação de baixas doses de glyphosate em eucalipto indicaram que a redução da atividade da enzima a níveis que elevaram a concentração de ácido chiquimico (ou chiquimato) em 278 vezes, implicou em um aumento de $69 \%$ (com efeito significativo ao nível de $1 \%$ de probabilidade) na taxa de crescimento de plantas jovens de eucalipto (este valor é uma média para os resultados de matéria seca de parte aérea e área foliar).

De modo coerente, informações de campo têm indicado que plantas intoxicadas acidentalmente com baixas doses de glyphosate apresentam menores níveis de resistência a doenças fúngicas e maior crescimento (Rizzardi et al., 2003; Power \& Swanton. 2008). 
Em áreas onde o herbicida glyphosate tem sido utilizado com frequiência, a população de espécies do gênero Commelina, popularmente conhecidas como trapoeraba, tem aumentado devido à tolerância às aplicações deste herbicida (Santos et al., 2001). C. benghalensis apresenta rápido crescimento, grande eficiência reprodutiva, seja por sementes ou por partes vegetativas do caule, sendo capaz de sobreviver nos mais diversificados ambientes (Santos et al., 2002).

Este trabalho teve por objetivo verificar o efeito de baixas doses do herbicida glyphosate no crescimento/desenvolvimento inicial da Commmelina benghalensis.

$\mathrm{O}$ experimento foi realizado em casa de vegetação no Núcleo de Pesquisas Avançadas em Matologia - NUPAM, pertencente ao Departamento de Produção Vegetal da Faculdade de Ciências Agronômicas/UNESP, Campus de Botucatu/SP.

Foram utilizados tubetes $\left(55 \mathrm{~cm}^{3}\right)$ preenchidos com substrato e em seguida foi realizada a semeadura da trapoeraba. A trapoeraba foi semeada superficialmente (aproximadamente $2 \mathrm{~cm}$ ), após terem sofrido escarificação mecânica, para quebra de dormência. Após a germinação deixou-se apenas uma planta por tubete.

Os tratamentos foram constituídos de diferentes doses de glyphosate, 2, 4, 8, 16, $20 \mathrm{e}$ 24 g e.a. ha ${ }^{-1}$ e uma testemunha sem aplicação

A aplicação do herbicida foi realizada através de um pulverizador estacionário instalado em laboratório e munido de uma barra contendo quatro pontas do tipo XR11.002. A pulverização foi realizada sobre pressão constante de 1,5 bar, pressurizado por ar comprimido, com consumo de calda de 200 $\mathrm{L} \mathrm{ha}^{-1}$.

Após a aplicação dos tratamentos, os tubetes foram irrigados com auxilio de pissetas de forma que o produto não fosse lavado da planta. As avaliações de crescimento foram realizadas aos 10 e 20 dias após aplicação do produto, através da destruição das plantas. Foram avaliados área foliar, área e diâmetro de raiz. Para tanto, as folhas foram separadas do caule, determinando-se a área foliar com o auxílio de uma régua (medindo cumprimento $\mathrm{x}$ altura). As raízes foram lavadas, para retirada do substrato e depois foram levadas ao laboratório para o escaneamento e posterior análise de crescimento feito através do software específico.

Os tratamentos foram dispostos em um delineamento experimental inteiramente casualizado, com dez repetições e os dados foram analisados através da análise de variância e os resultados significativos, ajustado por regressão.

Em resposta à aplicação de glyphosate aos 10 dias após a aplicação (DAA) para $C$. benghalensis, observou-se estímulo de crescimento em comprimento e área foliar, desde a menor dose até a maior, 24 g e.a. ha ${ }^{-1}$ (Figura1). Aos 20 DAA, a tendência de crescimento continuou a mesma, no entanto, os picos de crescimento ocorreram entre as doses 6 e 14 g e.a. ha ${ }^{-1}$, e para todas as doses de glyphosate aplicadas promoveram aumento na área foliar e comprimento quando comparada com a testemunha.

Resultados semelhantes foram obtidos por Mauch et al. (2001); Ruuhola \& JulkinenTitto (2003) e Velini et al. (2008), trabalhando com a aplicação de baixas doses de glyphosate em eucalipto observaram que a redução da atividade da enzima a níveis que elevaram a concentração de ácido chiquimico (ou chiquimato) em 278 vezes, implicou em um aumento de $69 \%$ (com efeito significativo ao nível de $1 \%$ de probabilidade) na taxa de crescimento de plantas jovens de eucalipto . 

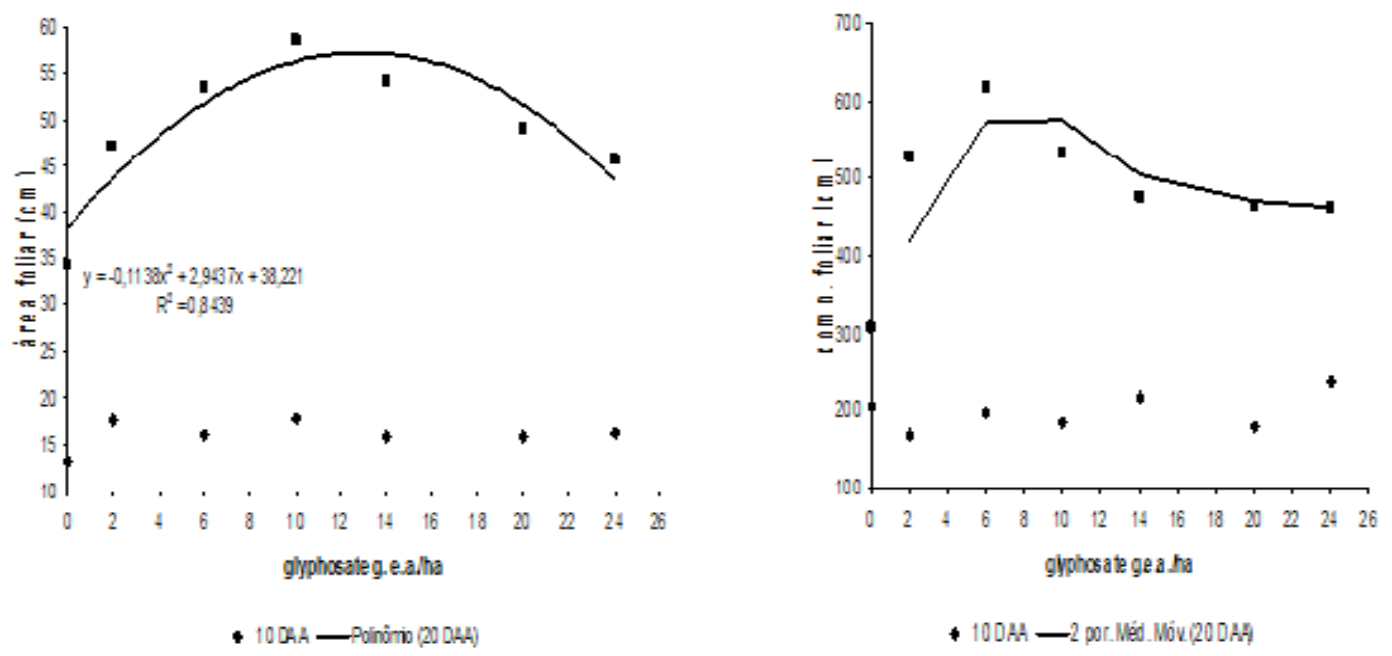

Figura 1. Média calculada de área foliar e comprimento de folha de Commelina benghalensis avaliadas 10 D.A.A. e 20 D.A.A. de subdoses de glyphosate. Botucatu/SP, 2006.

A área e comprimento do sistema radicular apresentam comportamento de crescimento semelhante, o maior crescimento foi observado na dose de $10 \mathrm{~g}$ e.a. ha ${ }^{-1}$ (Figura 2). Para as doses acima de $14 \mathrm{~g}$ e.a ha ${ }^{-1}$ promoveram efeito negativo sobre o crescimento do sistema radicular, indicando uma possível fitotoxicidade na raiz pelo acúmulo de glyphosate

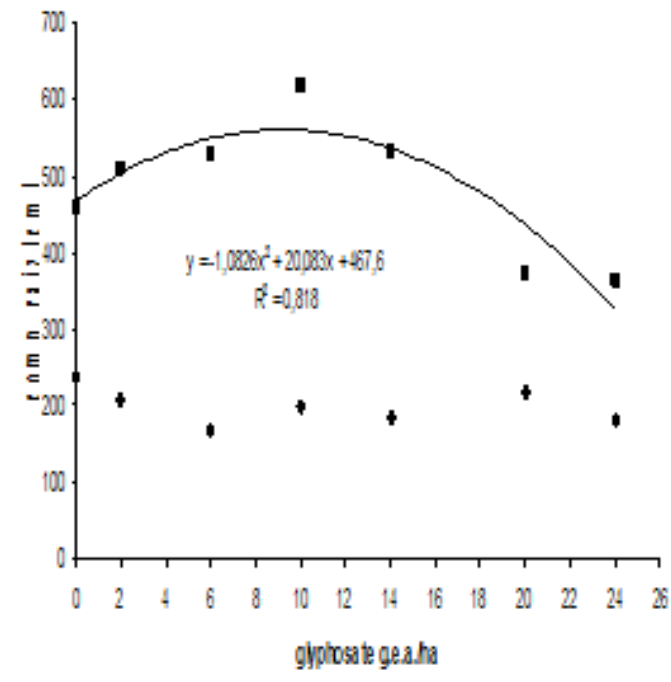

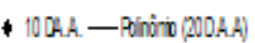

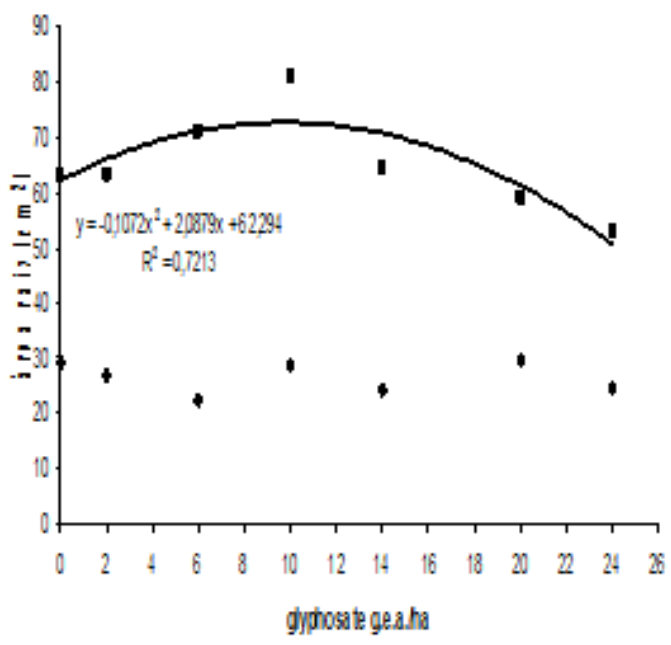

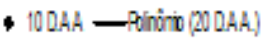

Figura 2. Área e Comprimento de raíz de Commelina benghalensis avaliadas aos 10 e 20 DAA de subdoses de glyphosate. Botucatu 2006

Para as características de crescimento dose de $6 \mathrm{~g}$ e.a. $\mathrm{ha}^{-1}$ as raízes tiveram seu de raiz verificou-se também que a partir da diâmetro incrementados, e que para as 
características de comprimentos e área de raiz não houve diferença em relação a testemunha, exceto que na dose de $24 \mathrm{~g}$ e.a. ha ${ }^{-1}$ verificouse um decréscimo de crescimento radicular, acusando uma possível fitotoxicidade nesta dosagem, mas sem no entanto refletir na parte aérea (Figura 3).

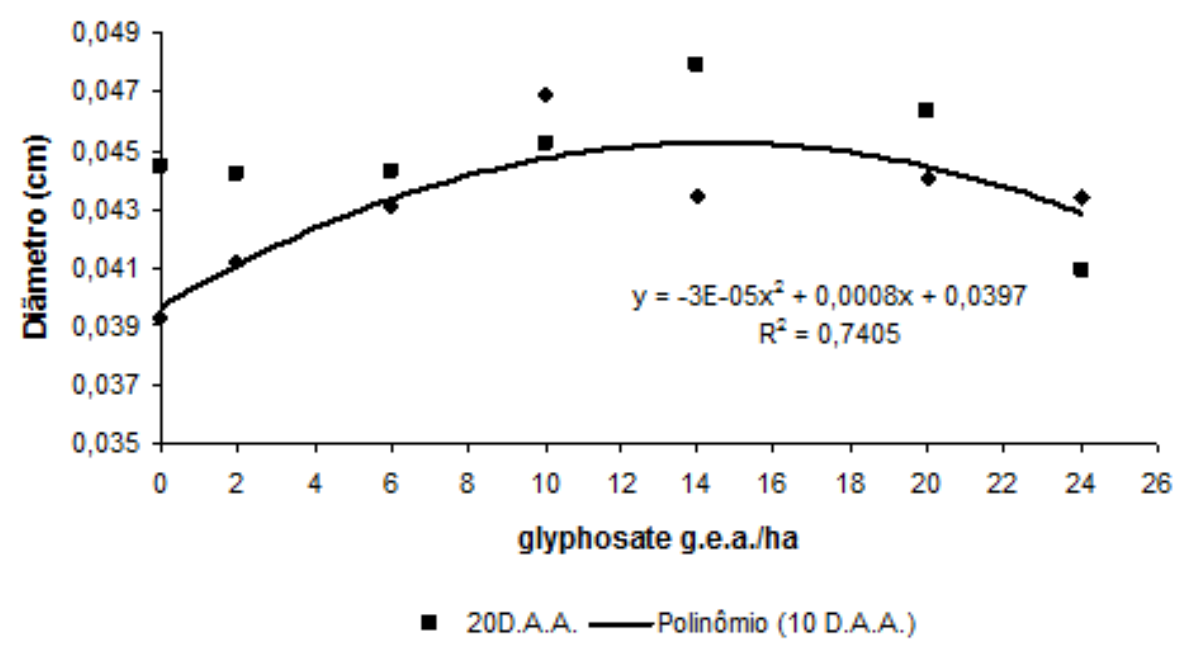

Figura 3. Diâmetro de Commelina benghalensis avaliadas aos 10 e 20 DAA de subdoses de glyphosate. Botucatu/SP, 2006.

Pelos resultados obtidos pode-se KRUSE, N.D.; MICHELANGELO, M.T.; verificar que em geral doses a partir de 2 g e.a. VIDAL, R. A. Herbicidas Inibidores da EPSPs: ha $^{-1}$ são capazes de causar efeitos sobre o revisão de literatura Revista Brasileira de crescimento e desenvolvimento da parte aérea e Herbicida, v.1, n.2, p.139-46, 2000.

radicular de plantas de $C$. benghalensis.

\section{Referências}

HALTER S. História do herbicida agrícola glyphosate. In: VELINI, E.D. et al. Glyphosate, 2009, Botucatu: FEPAF, 2009, p.11-16.

HESS, F.D. Herbicide effects on plant structure, physiology, struture, physiology, and biochemistry. In: Altman, J. Pesticide Interactions in Crop Production Beneficial and Deleterious Effects. CRC Press, London. 1993, 579p.

MAUCH, F. et al. Manipulation of salicylate content in Arabidopsis thaliana by the expression os an engineered bacterial salicylate synthase. Plant Journal, v.25, n.1, p.67-77, 2001.

MOUSDALE, D.M., COGGINS, J.R. Amino Acid Synthesis. In: Kirkwood, R.C. Target sites for herbicide action. Premium Press. New York. 1991, 339p.

PETERSON, M. L. et al. New simplified inhibitors of EPSP synthase: The importance of rinf size for recognition at the shikimate 3phosphate site. Bioorg. \& medic. Chem. v.6, n.23, p. 2853-58, 1996. 
POWELL, J. R.; SWANTON, C. J. A critique of studies evaluating glyphosate effects on diseases associated with Fusarium spp. Weed Research, v.48, n.4, p.307-318, 2008.

RUUHOLA, T., JULKINEN-TITO, R. Tradeoff between sinthesys of salicylicates and growth of micropropagated Salix pentandra. Journal of chemical Ecology, v.29, n.7, p.1565-1588, 2003.

RIZZARDI, M. A. et al. Ação de herbicidas sobre mecanismos de defesa das plantas aos patógenos. Ciência Rural, v.33, n.5, p.957965, 2003.

SANTOS, I. C. et al. Eficiência do herbicida glyphosate no controle de Commelina benghalensis e Commelina diffusa. Planta Daninha, v.19, n.1, p.135-143, 2001.

SANTOS, I. C. et al. Caracteres anatômicos de duas espécies de trapoeraba e a eficiência do glyphosate. Planta Daninha, v.20, n.1, p.1-8, 2002.

STAUFFER, M. E.; YOUNG, J. K.; HELMS, G. L.; EVANS, J. N. S. Chemical shift mapping of shikimate-3phosphate binding to the isolated N-terminal domain of 5enolpyruvylshikimate-3-phosphate synthase.

Federation of European Biochemical Societies. v.499, n.2 p. 182-86, 2001.

VELINI, E.D. et. al. Glyphosate applied at low doses can stimulate plant growth. Pest Management Science. v.65, n.4, p.317-460, 2008.

VELINI, E.D. et al. Modo de ação do glyphosate. In: VELINI, E.D. et al. Glyphosate. Botucatu: FEPAF, 2009, p.113134.

WARD, E.R. et al. Coordinate gene activity in response to agents thar induce systemis acquired resistance. The Plant Cell, v.3, n.3, p.1085-1094, 1991. 